\title{
Antimicrobial Resistance of Escherichia coli and Salmonella isolated from Raw Retail Broiler Chicken Carcasses in Zambia
}

Elizabeth Muligisa Muonga ( $\sim$ elizabethmuligisa@gmail.com )

Eden University Zambia, School of Health Sciences https://orcid.org/0000-0002-9480-1700

Geoffrey Mainda

Department of Veterinary Services-Public Health Unit, Ministry of Fisheries and Livestock, Lusaka, Zambia

\section{Mercy Mukuma}

Department of Food Science and Nutrition, School of Agricultural Sciences, University of Zambia, Lusaka, Zambia

\section{Geoffrey Kwenda}

Department of Biomedical Sciences, School of Health Sciences, University of Zambia, Lusaka, Zambia

\section{Bernard Hang'ombe}

Department of Paraclinical Studies, School of Veterinary Medicine, University of Zambia, Lusaka,

Zambia

Flavien Bumbangi

Department of Disease Control and Prevention, School of Medicine and Health Sciences, Eden University, Lusaka, Zambia

\section{Nelson Phiri}

Department of Environmental Health, School of Medicine and Health Sciences, Eden University, Lusaka, Zambia

\section{Mwaba Mwansa}

Department of Basic Sciences, School of Medicine, Copperbelt University, Ndola, Zambia

\section{Musso Munyeme}

Department of Disease Control, School of Veterinary Medicine, University of Zambia, Lusaka, Zambia John Bwalya Muma

University of Zambia School of Medicine

\section{Research article}

Keywords: Antimicrobial resistance, E. coli, Salmonella, Poultry, Zambia 
DOI: https://doi.org/10.21203/rs.2.14062/v2

License: (c) (1) This work is licensed under a Creative Commons Attribution 4.0 International License. Read Full License

Version of Record: A version of this preprint was published at Journal of Epidemiological Research on May 21st, 2021. See the published version at https://doi.org/10.5430/jer.v6n1p35. 


\section{Abstract}

\section{Background}

Antimicrobial resistance (AMR) of foodborne pathogens is of public health concern, especially in developing countries such as Zambia. This study was undertaken to determine the antimicrobial resistance profiles of Escherichia coli ( E. coli) and Salmonella isolated from raw retail broiler chicken carcasses purchased from open and supermarkets in Zambia.

Results

A total of $189 \mathrm{E}$. coli and five Salmonella isolates were isolated. Identification and confirmation of the isolates were done using Analytical Profile Index (API 20E) (Biomerieux ( ) and 16S rRNA sequencing. Antimicrobial susceptibility tests (AST) were performed using the Kirby Bauer disk diffusion technique using a panel of 10 antibiotics. Multiplex PCR was used to determine the presence of three target genes encoding for resistance: tet A, Sul 1 and bla CTX-M . WHONET 2018 software was used to analyse AST results. The E. coli isolates were mostly resistant to tetracycline (79.4\%), ampicillin (51.9\%), and trimethoprim/sulfamethoxazole (49.7\%). Two of the five Salmonella isolates were resistant to at least one antibiotic. Forty- seven (45.2\%) of the 104 isolates that were screened for the presence of the resistant genes possessed at least one of the targeted resistance genes.

Conclusion

This study has demonstrated the presence of AMR E. coli and Salmonella on raw retail broiler chicken carcasses from open and supermarkets, which is of public health concern.

\section{Background}

Poultry meat forms an integral part of the diet, especially in developing countries. It is popular because it is a cheaper source of protein and easy to produce compared to other meat products (Musaba and Mseteka, 2014). However, the high demand for poultry meat puts a strain on producers, who have to meet the ever-growing demand and also realise profits in a competitive market environment (Ahuja and Sen, 2007). One of the strategies producers often resort to is the use of antibiotics to prevent and treat diseases of poultry to optimize growth (Apata, 2009).

Antibiotics are also used for growth promotion. However, if they are misused, they can lead to the development of resistance in bacteria found in chickens. In the absence of a national surveillance system on the use of antibiotics, it is difficult to know whether they are being used appropriately (WHO Global Report, 2014).

In monitoring development of antimicrobial resistance (AMR) in bacteria, Escherichia coli (E. coli) is commonly used because it is part of the gut microbiota and is a reservoir for AMR genes (Van Schaik, 2015; Yassin et al., 2017). AMR occurs when bacteria, viruses, fungi and parasites no longer respond to 
the antimicrobials designed to kill them (Centers for Disease Control and Prevention, 2018). Despite $E$. coli being an innocuous resident of the digestive system, it can also be pathogenic and cause severe intestinal and extra-intestinal diseases (Diarrassouba et al., 2007). Recent studies showed that $E$. coli is involved in 48 million reported cases of foodborne illness worldwide (CDC, 2016). Furthermore, among the foodborne bacterial enteropathogens, E. coli, Salmonella sp. and Campylobacter sp. are responsible for most of the diarrhoeal diseases that affect millions of people annually, sometimes with fatal outcomes (WHO, 2015).

Besides, non-typhoidal Salmonella species are responsible for causing gastroenteritis and bacteremia, which can eventually lead to secondary infection, especially in immune-compromised individuals such as patients with malignancy, human immunodeficiency virus, diabetes, and those receiving medication for anti-inflammatory diseases (Gordon, 2008).

E. coli and Salmonella sp. infections can be treated using relevant antibiotics. However, there is accumulating evidence of the consequences of AMR including, the reduction in the efficacy of treatment with first-line drugs and limited choices after microbiological diagnosis (Clarke et al., 2012; Mshana et al, 2013).

In Zambia, recent findings showed that Salmonella sp. and E. coli (18\% and $25.5 \%$, respectively) were among the most detected organisms causing bacterial diarrhoeal disease in children between the ages of 0-59 months at the University Teaching Hospital (Chiyangi et al., 2017). In this age category, most of the diarrhoeal cases are more likely to be caused by foodborne pathogens especially in developing countries where food safety problems and poor hygiene and sanitation are recurrent (Byarugaba, 2004; Thapar and Sanderson, 2004).

Further, several reports from different countries elucidate a growing concern of AMR in foodborne pathogens which have a negative impact on public health (Clarke et al., 2012; Mshana et al, 2013; Mainda et al., 2015). However, there is a paucity of information on AMR occurrence on foodborne pathogens in Zambia. Furthermore, in a growing industry of broiler chicken production and consumption in Zambia, the misuse of antimicrobials for growth promotion, prevention and treatment of diseases could contribute to the occurrence of AMR in foodborne pathogens; yet few studies have been conducted to ascertain the magnitude of the problem and generate information that could address the AMR problem.

This study, therefore, aimed at characterizing the phenotypes and genotypes of antimicrobial-resistant $E$. coli and Salmonella on raw retail broiler chicken carcasses in Zambia.

\section{Results}

A total of 332 raw retail broiler chicken carcasses were sampled from both supermarkets (154) and open markets (178), from which 189 (56.9\%) and 05 (1.5\%) E. coli and Salmonella, respectively were isolated and identified. The two pathogens of interest were mostly isolated from supermarkets (Table 2). 
Table 2: Distribution of isolates according to market types and district

\begin{tabular}{|c|c|c|c|c|c|c|}
\hline \multirow[t]{2}{*}{ District } & \multicolumn{3}{|c|}{ Open Market } & \multicolumn{3}{|c|}{ Supermarket } \\
\hline & No. of samples & $\begin{array}{c}\text { No. of E. coli } \\
(\%)\end{array}$ & $\begin{array}{c}\text { No. of Salmonella } \\
(\%)\end{array}$ & No. of samples & $\begin{array}{c}\text { No. of E. coli } \\
(\%)\end{array}$ & $\begin{array}{c}\text { No. of Salmonella } \\
(\%)\end{array}$ \\
\hline Chilanga & 8 & $0(0.0)$ & 0 & 4 & $4(100.0)$ & 0 \\
\hline Chongwe & 11 & $4(36.4)$ & 0 & 0 & 0 & 0 \\
\hline Kafue & 2 & $2(100.0)$ & 0 & 6 & $6(100.0)$ & 0 \\
\hline Lusaka & 113 & $73(64.6)$ & 1 & 106 & 59 (55.7) & 4 \\
\hline Kitwe & 15 & $8(53.3)$ & 0 & 18 & 15 (83.3) & 0 \\
\hline Choma & 14 & $7(50.0)$ & 0 & 7 & $5(71.4)$ & 0 \\
\hline Kabwe & 15 & $2(13.3)$ & 0 & 13 & $4(30.8)$ & 0 \\
\hline Total & 178 & $96(53.9)$ & $1(0.5)$ & 154 & $93(60.4)$ & $4(2.6)$ \\
\hline
\end{tabular}

\section{Antimicrobial susceptibility profiles}

E. coli isolates from raw retail broiler chicken carcasses obtained from open markets had a higher occurrence of resistance of $91.7 \%(n=88)$ to at least one antimicrobial agent in the AST testing, while those from supermarkets recorded $83.9 \%(n=78)$. The overall resistance of $E$. coli isolates to at least one antimicrobial agent for both the open markets and supermarkets was $88 \%(n=166)$. However, 102 E. coli and the 02 Salmonella isolates were completely resistant to at least one of the antimicrobials used. The E. coli isolates were resistant to tetracycline, trimethoprim-sulfamethoxazole and ampicillin with $79.4 \%$ ( $n=150$ isolates), $51.9 \%$ ( $n=98$ isolates) and $49.7 \%$ ( $n=94$ isolates) resistance, respectively (Table 3) while only ampicillin and tetracycline recorded resistance among the Salmonella isolates (Table 4).

Table 3: Resistance profiles for E. coli isolates $(\mathrm{n}=189)$

\begin{tabular}{lcccccc}
\hline \multicolumn{1}{c}{ Antimicrobial } & $\begin{array}{c}\text { Breakpoints } \\
(\mathrm{mm})\end{array}$ & Number & \%R & \%I & \%S & \% R 95\%C.I. \\
\hline Ampicillin & $14-16$ & 189 & 51.9 & 4.8 & 43.4 & $44.5-59.2$ \\
Amoxicillin/Clavulanic acid & $14-17$ & 189 & 6.9 & 5.8 & 87.3 & $3.9-11.8$ \\
\hline Cefotaxime & $23-25$ & 189 & 16.4 & 6.3 & 77.2 & $11.6-22.6$ \\
\hline Imipenem & $20-22$ & 189 & 1.1 & 6.3 & 92.6 & $0.2-4.2$ \\
\hline Nalidixic acid & $14-18$ & 189 & 24.3 & 9.5 & 66.1 & $18.5-31.2$ \\
\hline Ciprofloxacin & $16-20$ & 189 & 10.1 & 4.2 & 85.7 & $6.4-15.5$ \\
\hline Trimethoprim/Sulfamethoxazole & $11-15$ & 189 & 49.7 & 0.5 & 49.7 & $42.4-57.0$ \\
\hline Chloramphenicol & $13-17$ & 189 & 16.4 & 4.8 & 78.8 & $11.6-22.6$ \\
\hline Tetracycline & $12-14$ & 189 & 79.4 & 2.1 & 18.5 & $72.8-84.8$ \\
\hline
\end{tabular}


Table 4: Resistance profiles for Salmonella isolates $(n=5)$

\begin{tabular}{lcccccc}
\hline \multicolumn{1}{c}{ Antimicrobial } & $\begin{array}{c}\text { Breakpoints } \\
(\mathrm{mm})\end{array}$ & Number & $\% \mathrm{R}$ & $\% \mathrm{IS}$ & $\begin{array}{c}\% \mathrm{R} \\
\text { 95\%C.I. }\end{array}$ \\
\hline Ampicillin & $14-16$ & 5 & 60 & 0 & 40 & $\begin{array}{c}17.0-92.7 \\
\text { Amoxicillin/Clavulanic acid }\end{array}$ \\
\hline Cefotaxime & $14-17$ & 5 & 0 & 20 & 80 & $0.0-53.7$ \\
\hline Imipenem & $23-25$ & 5 & 0 & 20 & 80 & $0.0-53.7$ \\
\hline Nalidixic acid & $20-22$ & 5 & 0 & 0 & 100 & $0.0-53.7$ \\
\hline Ciprofloxacin & $14-18$ & 5 & 0 & 20 & 80 & $0.0-53.7$ \\
\hline Trimethoprim/Sulfamethoxazole & $11-15$ & 5 & 0 & 0 & 100 & $0.0-53.7$ \\
\hline Chloramphenicol & $13-17$ & 5 & 0 & 0 & 100 & $0.0-53.7$ \\
\hline Tetracycline & $12-14$ & 5 & 40 & 20 & 40 & $7.3-83.0$ \\
\hline
\end{tabular}

None of the Salmonella isolates was Multidrug-resistant (MDR). MDR was defined as acquired nonsusceptibility to at least one agent in three or more antimicrobial categories (Basak et al, 2016) However, 36.5\% ( $n=69)$ of the E. coli isolates were MDR and 26 different patterns were observed (Table 5). The most common MDR patterns that were observed among the $E$. coli isolates were CHL-TCY-AMP-SXT (15.9\%), CTX -TCY-AMP-SXT (10.1\%), CIP-TCY-AMP-SXT (8.7\%).

Table 5: Antimicrobial Resistance Patterns for MDR isolates. 


\begin{tabular}{|c|c|}
\hline Antimicrobial Resistance Pattern & Number of isolates with the pattern $(n, \%)$ \\
\hline CTX-TCY-AMP & $2(2.9 \%)$ \\
\hline CHL-TCY-SXT & $2(2.9 \%)$ \\
\hline CHL-TCY-AMP & $3(4.3 \%)$ \\
\hline CHL-CTX-TCY & $1(1.4 \%)$ \\
\hline CHL-CIP-TCY & $1(1.4 \%)$ \\
\hline TCY-AMP-SXT & $2(2.9 \%)$ \\
\hline IPM-TCY-AMP-SXT & $1(1.4 \%)$ \\
\hline CTX-TCY-AMP-SXT & $7(10.1 \%)$ \\
\hline CTX-IPM-TCY-SXT & $4(5.8 \%)$ \\
\hline CIP-TCY-AMP-SXT & $6(8.7 \%)$ \\
\hline CIP-IPM-AMP-SXT & $1(1.4 \%)$ \\
\hline CIP-CTX-TCY-SXT & $2(2.9 \%)$ \\
\hline CIP-CTX-TCY & $1(1.4 \%)$ \\
\hline CHL-TCY-AMP-SXT & $11(15.9 \%)$ \\
\hline CHL-CTX-AMP-SXT & $1(1.4 \%)$ \\
\hline CHL-CTX-TCY-SXT & $1(1.4 \%)$ \\
\hline CHL-CIP-TCY-SXT & $3(4.3 \%)$ \\
\hline CTX-TCY-AMP-SXT & $1(1.4 \%)$ \\
\hline CIP-IPM-TCY-AMP-SXT & $1(1.4 \%)$ \\
\hline CHL-IPM-TCY-AMP & $2(2.9 \%)$ \\
\hline CHL-CTX-TCY-AMP-SXT & $4(5.8 \%)$ \\
\hline CHL-CIP-TCY-AMP-SXT & $5(7.2 \%)$ \\
\hline CHL-CIP-IPM-TCY-AMP-SXT & $1(1.4 \%)$ \\
\hline CHL-CIP-CTX-TCY-AMP-SXT & $4(5.8 \%)$ \\
\hline IPM-TCY-SXT & $1(1.4 \%)$ \\
\hline CTX-TCY-SXT & $1(1.4 \%)$ \\
\hline Total MDR & $69(99.2 \%)$ \\
\hline
\end{tabular}

\section{Determination of Antimicrobial resistance genes}

Due to limited resources, only $102 \mathrm{E}$. coli and 2 Salmonella isolates that were completely resistant to at least one of the antimicrobials used were analyzed for the presence of resistance genes. The presence of at least one of the targeted genes was detected in $45.2 \%(n=47)$ of the E. coli isolates. The Salmonella isolates did not show the presence of the targeted genes. The beta-lactamase-encoding genes $\left(b / a_{\mathrm{CTX}-\mathrm{M}}\right)$ were the most commonly detected among the $47 \mathrm{E}$. coli isolates. 


\section{Discussion}

This study isolated $E$. coli and Salmonella from raw retail broiler chicken carcasses traded in supermarkets and open markets in selected districts in Zambia. It further characterized the phenotypes and genotypes of AMR phenotypes and genotypes of E. coli and Salmonella isolates.

It was observed that the recovery rate of E. coli and Salmonella sp was higher in samples from supermarkets ( $60.4 \%$ and $2.6 \%$, respectively) as compared to those from open markets. These findings are different from those of a similar study conducted in Thailand where authors reported a low recovery rate of $25 \%$ and $2 \%$ for $E$. coli and Salmonella, respectively (Vindigni et al., 2007). The disparity of findings could be attributed to a difference in processing methods and commercial production techniques which are highly automated in Thailand as compared to the Zambian settings where the manual system is often used hence exposing the carcasses to contamination.

The overall contamination level of Salmonella sp in all samples was low (1.5\%). This was also observed in some studies done at the retail level (Cosby et al., 2015; Mpundu et al., 2019). The low contamination rate could be attributed to the intermittent shading of Salmonella in poultry (Van Immerseel et al., 2004).

E. coli and Salmonella sp. isolated from this study showed a high level of antibiotic resistance including resistance to multiple antibiotics. E. coli isolates were resistant to tetracycline (79.4\%), ampicillin (51.9\%) and trimethoprim/sulfamethoxazole (49.7\%). This has also been observed in other parts of the world (Talebiyan et al., 2014) and could be attributed to the use of these antibiotics as growth promotors and for prevention of infection rather than for therapeutic purposes only (Agyare et al., 2019). Salmonella isolates were resistant to ampicillin (60.0\%) and tetracycline (40.0\%). Similar resistance profiles for Salmonella isolated from food animals was reported by Johnson et al. (2005) in a study conducted in Canada (Johnson et al, 2005).

The high resistance to tetracyclines, sulfonamides and beta-lactam antibiotics could be attributed to the abuse of antibiotics in both livestock and humans, especially among small poultry producers. In Zambia, there is poor regulation of veterinary drugs and antibiotics, whereby farmers can purchase antibiotics over the counter without a prescription (Mainda, 2016; Manyi-Loh et al., 2018). Further, the poor hygienic processing methods that are employed by small and medium-scale producers may facilitate the contamination of the carcasses with AMR organisms. The handling of the carcasses during slaughter, rinsing, transportation and sale may also introduce resistant organisms from humans and the environment into the carcasses. Raw retail broiler chicken carcasses that originate from commercial abattoirs, however, may get contaminated mostly from the abattoir bench surfaces and intestines of the broilers during processing (Voidarou et al., 2011).

Multidrug resistance was also reported among 69 (36.5\%) of the 189 E. coli isolates in this study. These findings are similar to other studies on AMR in both poultry and humans (van den Bogaard, 2001; Chiyangi et al., 2017). The high resistance in poultry, especially, can be attributed to the use of antibiotics for preventive purposes by small-scale poultry farmers between weeks 4 and 6 of production to prevent 
high mortality rates due to colibacillosis in broilers (Nolan et al., 2017). It has also been documented that tetracycline and sulfadimidine are among the commonly used antibiotics for therapy, especially at smallscale production (Mainda et al., 2015). Further, farmers tend to self-prescribe these drugs whenever they have a disease situation when raising the birds (Guetiya Wadoum et al., 2016; Xu et al., 2020). Such misuse of antibiotics in livestock production has been reported to cause AMR (Lowe, 1982; Ngoma et al., 1993; Koluman and Dikici, 2013; Kalonda et al., 2015; Ayukekbong et al, 2017).

Of the three resistant genes that were targeted, the beta-lactams gene (b/a $a_{\text {CTX-M }}$ gene) was the most detected in this study. E. coli strains harbouring these genes have been detected in both healthy and sick poultry (Girlich et al., 2007) and are an indication of Extended-Spectrum Beta-Lactamase (ESBL)

producing E. coli. The beta-lactam gene of interest that was targeted is similar to the one that was found by other researchers who did similar studies (Chishimba et al., 2016; Ramachandran et al, 2017). Though the other two genes for resistance to sulfonamides and tetracyclines (sul1 and tetA) were also detected, the detection rates were not as high as that of the beta-lactamase-encoding gene of interest. These discrepancies could be attributed to differences in target sequences of the resistance genes that were being targeted or other genes other than the ones chosen for this study.

Although the scope of molecular analysis was limited in this study the indication is that most phenotypic resistance that was observed in E. coli and Salmonella isolates were encoded by the genes that encodes tetracyclines, beta lactams and sulphur based antibiotics. These antibiotics have been reported to be the most commonly used in Zambia and are relatively preferred because of the affordable price by most livestock (Mainda et al., 2015).

\section{Conclusion}

This study has demonstrated the presence of AMR E. coli and Salmonella on raw retail broiler chicken carcasses in selected districts in Zambia. It has also shown the presence of MDR and ESBL producing $E$. coli that are of public health concern, if acquired by humans. The E. coli and Salmonella isolates were most resistant to tetracyclines, beta-lactams, sulfonamide and fluoroquinolone antibiotics. This could be attributed to the misuse of antibiotics at both commercial and small-scale levels of production. There is a need to regulate the use of antibiotics during broiler chicken production. Further, more molecular work that can give a complete understanding of the actual genes conferring resistance in Zambia will be beneficial to guide AMR policy formulation.

\section{Methods}

\section{Study Design}

A cross-sectional study was conducted between August 2017 and May 2018 in seven districts in Zambia that included Lusaka, Chilanga, Chongwe, Kafue, Choma, Kabwe and Kitwe. Choma, Kabwe, Kitwe and Lusaka districts were purposely selected because as provincial headquarters, they are retail destinations 
for many poultry products from other districts while Chilanga, Chongwe and Kafue districts were included due to their proximity to Lusaka, the capital city. The primary sampling units were the markets (broadly classified as Open markets and Supermarkets) and the secondary sampling units were the raw retail broiler chicken carcasses. An open market was defined as an unrestricted market, not housed in a building, where food products are often sold exposed, while a supermarket was defined as a restricted market, housed in a closed building with modernized facilities (Bumbangi et al., 2016).

Proportion stratified random sampling was employed where Open markets and Supermarkets were the strata. At the time of the study, information collected from the respective City Councils revealed that there were 47 supermarkets and 33 open markets in Lusaka province, five open markets and four supermarkets in Choma, seven open markets and eight supermarkets in Kitwe, nine open markets and six supermarkets in Kabwe, three open markets and two supermarkets in Kafue, three open markets and one supermarket in Chilanga, and one open market and no supermarket in Chongwe. This formed the sampling frame from which a study population was drawn.

\section{Sample size calculation}

The sample size for estimation of a single proportion was calculated using Epi tools software (www.epitools.ausvet.com) based on the following assumptions: prevalence of AMR E. coli on raw retail broiler chicken carcasses $=25 \%$ (Vindigni et al., 2007); confidence level $=95 \%$; level of precision $=5 \%$. Using the above assumptions, the minimum sample size calculated was 289 and the distribution of sampling sites is as outlined in Table 1.

\section{Sampling from open markets}

From the open markets within Lusaka district that were sampled $(n=22)$, two shops trading in raw retail broiler chicken carcasses at each market were selected and from each shop two raw retail broiler chicken carcasses purchased. Furthermore, at the market where open stands (display tables) instead of shops trading in dressed broiler chickens were available, one sample from each stand was collected. For other districts, considering the limited number of markets that traded in raw retail broiler chicken carcasses, all of them were included in the study and at least two samples from each market were collected bringing the total number of samples from open markets to 178 (Table 1).

\section{Sampling from the Supermarket}

From each supermarket in all districts, a maximum of four different brands of raw retail broiler chicken carcasses was sampled (one of each brand), though some sampling sites had less than the maximum number. Therefore, the number of broiler carcasses from supermarkets in this study was 154 (Table 1).

Table 1: Summary distribution of samples collected by market type and district 


\begin{tabular}{lllllll} 
District & $\begin{array}{l}\text { No. of } \\
\text { Open } \\
\text { Markets }\end{array}$ & $\begin{array}{l}\text { No. of } \\
\text { Supermarkets }\end{array}$ & $\begin{array}{l}\text { Total } \\
\text { No. of } \\
\text { Markets }\end{array}$ & $\begin{array}{l}\text { Samples from } \\
\text { Open Markets } \\
(\%)\end{array}$ & $\begin{array}{l}\text { Samples from } \\
\text { Supermarkets } \\
(\%)\end{array}$ & $\begin{array}{l}\text { Total No. } \\
\text { of } \\
\text { samples } \\
(\%)\end{array}$ \\
\hline Chilanga & 2 & 1 & 3 & $8(4.5)$ & $4(2.6)$ & $12(3.6)$ \\
\hline Chongwe & 1 & 0 & 1 & $11(6.2)$ & $0(0.0)$ & $11(3.3)$ \\
\hline Kafue & 1 & 2 & 3 & $2(1.1)$ & $6(3.9)$ & $8(2.4)$ \\
\hline Lusaka & 22 & 34 & 56 & $113(63.5)$ & $106(68.8)$ & $219(66.0)$ \\
\hline Kitwe & 7 & 8 & 15 & $15(8.4)$ & $18(11.7)$ & $33(9.9)$ \\
\hline Choma & 4 & 2 & 6 & $14(7.9)$ & $7(4.5)$ & $21(6.3)$ \\
\hline Kabwe & 5 & 3 & 8 & $15(8.4)$ & $13(8.5)$ & $28(8.5)$ \\
\hline Total & $\mathbf{4 2}$ & $\mathbf{5 0}$ & $\mathbf{9 2}$ & $\mathbf{1 7 8 ( 1 0 0 . 0 )}$ & $\mathbf{1 5 4 ( 1 0 0 . 0 )}$ & $\mathbf{3 3 2}$ \\
\hline
\end{tabular}

Upon purchase, all samples were transported in a cooler box containing ice packs to the laboratory and processed within 8 hours.

\section{Laboratory Analysis}

Laboratory isolation included a whole carcass rinse in buffered peptone water (Oxoid) (Figure S1a-c), preenrichment of an aliquot of the rinsate and subsequent incubation at $37^{\circ} \mathrm{C}$ overnight. Processing of preenriched broths was undertaken in the Public Health Laboratory, School of Veterinary Medicine. The Carcass Rinse technique outlined by the USDA Food Safety and Inspection Service was used with a few modifications (D'Aoust et al, 1982). Whole chicken carcasses were aseptically placed in sterile 3 litre ziplock bags. $450 \mathrm{~mL}$ of sterile buffered peptone water (Oxoid UK) was poured into each of the bags containing the carcasses. The open ends of the bags were then twisted to hold the bags closed and the entire carcass was rinsed using a repeated rocking motion 30 times. The bags were then opened and the carcasses removed. The rinsate was then collected in sterile containers by puncturing the " $v$ "-end of the bags and used for further analysis.

The methods proposed by the Food and Drug Administration's Bacteriological Analytical Manual (U.S. Food and Drug Administration, 2001) were used with a few modifications for the isolation of Salmonella and E. coli. During the carcass rinse technique, $450 \mathrm{~mL}$ of sterile buffered peptone water was also poured into an empty bag that did not contain a carcass to act as a control. The rinsate was incubated overnight and later streaked onto MacConkey agar plate (Oxoid, UK) to ensure that the batch of bags was sterile and that the organisms isolated were indeed from the chicken carcasses and not the bags used for rinsing. $10 \mu \mathrm{L}$ of the incubated broth was then transferred to MacConkey agar (Oxoid UK) and resulting colonies were gram stained for detection of Gram-negative short rods, which were subsequently subcultured onto Eosin Methylene Blue (EMB) agar (Oxoid UK). Colonies that showed a metallic green sheen 
(Figure S2) were subjected to biochemical tests using Analytical Profile Index (API 20E) (Biomerieux ${ }^{\circledR}$ ) for identification for $E$. coli isolates. $1 \mathrm{ml}$ of the incubated pre-enrichment broth was also transferred to Rappaport Vassiliadis (Oxoid UK) and later subcultured on Xylose-Lysine Deoxycholate agar (Oxoid UK). Pink and black colonies on XLD agar (Figure S3) were then Gram-stained and subjected to biochemical tests for identification of Salmonella using API 20E. Further confirmation of the isolates was done using 16S rRNA sequencing (Weisburg et al., 1991).

The Kirby-Bauer disk diffusion technique for AST was used on all confirmed Salmonella and E. coli isolates (Figure S4) using a panel of 10 different antibiotics (Kirby-Bauer, 1961). The isolates were prepared by sub-culturing onto Blood agar (Oxoid UK) overnight at $37^{\circ} \mathrm{C}$. One or two colonies were then suspended in $4 \mathrm{~mL}$ of $0.9 \%$ sodium chloride solution and their turbidity compared to that of a 0.5 McFarland's turbidity standard. An inoculum of the suspension was then spread on two Müeller Hinton agar ( $4 \mathrm{ml}$ thickness) plates (Oxoid UK) until the entire surfaces of the plates were covered. 5 different antibiotic wafers from the 10 chosen for the study were then placed on the surface of each of 2 plates using the applicator (Oxoid). Two plates were used for each isolate to accommodate the 10 antibiotics. The antibiotics that were used were amoxicillin-clavulanic acid $(30 \mu \mathrm{g})$, ampicillin $(10 \mu \mathrm{g})$, cefotaxime $(30 \mu \mathrm{g})$, chloramphenicol $(30 \mu \mathrm{g})$, ciprofloxacin $(5 \mu \mathrm{g})$, colistin sulphate $(10 \mu \mathrm{g})$, imipenem $(10 \mu \mathrm{g})$, nalidixic acid $(30 \mu \mathrm{g})$, tetracycline $(30 \mu \mathrm{g})$ and trimethoprim-sulfamethoxazole $(25 \mu \mathrm{g})$. The list of antibiotics was prioritized based on the most frequently used in the poultry industry in Zambia and also based on the priority list by the WHO and OIE of critical antibiotics (Oie, 2007; WHO, 2017). The plates were then incubated at $37^{\circ} \mathrm{C}$ for $24 \mathrm{hrs}$ and the diameters of the zones of inhibition entered and analyzed in WHONET 2018 software. An isolate was considered to be completely resistant to an antimicrobial when it had no zone of inhibition around the antimicrobial disc after the incubation (Kirby-Bauer, 1961). The interpretation of AST results was based on the Clinical and laboratory standards institute (CLSI) guidelines 2018 (Replaces et al., 2018)

Isolates which showed resistance to tetracyclines, sulphonamides and beta-lactam antibiotics were then forwarded for molecular analysis that involved extraction of DNA and checking for the presence of target resistance genes. The process of DNA extraction involved the suspension of a few bacterial colonies in $100 \mu \mathrm{L}$ of nuclease-free water and heating of the vials at $80^{\circ} \mathrm{C}$ for 10 minutes. The suspension was then centrifuged at $60000 \mathrm{G}$ with a temperature of $4^{\circ} \mathrm{C}$ for 3 minutes. Multiplex polymerase chain reaction (PCR) was performed to check the presence of resistant genes of interest according to the method described by Adesiji et al. 2014. The mastermix volumes and PCR reaction were as outlined in Table S1 and Table S2 (Supplementary Material). The target genes were selected based on the antimicrobial susceptibility results. The 3 target genes were tetA (for tetracycline resistance), sul1 (for sulfonamide

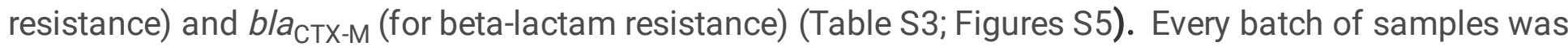
processed along with a positive and negative control using E. coli 25922 (ATCC) and Salmonella typhimurium 14028 (ATCC).

\section{Declarations}




\section{Ethics approval and consent to participate}

Ethical approval was given by ERES Converge IRB under the WHO-AGISAR project titled Investigation of foodborne pathogens and their antimicrobial resistance in animals and humans - A pilot project for Zambia (ID: 204954).

\section{Consent for publication}

Not applicable

\section{Availability of Data and Supporting Materials}

The datasets supporting the conclusions of this article are available within the article (Tables) and separate data files uploaded (Figures). Any additional datasets required are available from the corresponding author on request.

\section{Conflict of Interest}

The authors declare that there is no conflict of interest regarding this publication.

\section{Funding}

The research was funded by the WHO-funded Advisory Group for Integrated Surveillance of Antimicrobial Resistance (AGISAR) Project, the World Bank-funded African Centre of Excellence in Infectious Diseases of Humans and Animals (ACEIDHA) programme and The Capacity Building in Zoonotic Disease Management Using Integrated Ecosystems Health Approach at the Human-Livestock-Wildlife Interface in the Eastern and Southern Africa (CAPAZOMANINTECO), under the NOHERD project

\section{Author's contributions}

Elizabeth Muligisa-Muonga was the principle investigator, Geoffrey Mainda, Musso Munyeme, Geoffrey Kwenda and Flavien Bumbangi edited the document, Nelson Phiri and Mwaba Mwansa helped with sample collection and processing, Bernard Hang'ombe and Mercy Mukuma were co-supervisors while John Muma was the principle supervisor and recipient of the funds that ensured the completion of the research.

\section{Acknowledgements}

We would like to thank Mr Joseph Ndebe; Mr Penjani Kapila; Mr Patrick Katemangwe; Mrs Lweendo Hachamba-Sachikolo and Miss. Yambilani Nyirenda for the help rendered during sample processing. We would also like to thank the WHO-funded Advisory Group for Integrated Surveillance of Antimicrobial Resistance (AGISAR) Project at the University of Zambia and the World Bank-funded African Centre of Excellence in Infectious Diseases of Humans and Animals (ACEIDHA) programme for the provision of funds and research materials required for laboratory sample analysis and The Capacity Building in 
Zoonotic Disease Management Using Integrated Ecosystems Health Approach at the Human-LivestockWildlife Interface in the Eastern and Southern Africa (CAPAZOMANINTECO), under the NOHERD project, for sponsoring part of the research work. Our sincere gratitude also goes out to the technical staff at the Department of Disease Control, and Department of Paraclinical Studies at the University of Zambia, School of veterinary medicine for their technical support and guidance they rendered to us during my study.

\section{References}

Adesiji, Y. O., Deekshit, V. K. and Karunasagar, I. (2014) 'Antimicrobial-resistant genes associated with Salmonella spp . isolated from human , poultry, and seafood sources'. doi: 10.1002/fsn3.119.

Agyare, C. et al. (2019) 'Antibiotic Use in Poultry Production and Its Effects on Bacterial Resistance', in Antimicrobial Resistance - A Global Threat. doi: 10.5772/intechopen.79371.

Ahuja, V. and Sen, A. (2007) 'Scope and Space for small scale poultry production in developing countries', Management. doi: 10.1080/00045608.2011.652888.

Apata, D. F. (2009) 'Antibiotic resistance in poultry', International Journal of Poultry Science. doi: 10.3923/ijps.2009.404.408.

Ayukekbong, J. A., Ntemgwa, M. and Atabe, A. N. (2017) 'The threat of antimicrobial resistance in developing countries: Causes and control strategies', Antimicrobial Resistance and Infection Control. doi: 10.1186/s13756-017-0208-x.

Basak, S., Singh, P. and Rajurkar, M. (2016) 'Multidrug Resistant and Extensively Drug Resistant Bacteria: A Study', Journal of Pathogens. doi: 10.1155/2016/4065603.

van den Bogaard, A. E. (2001) 'Antibiotic resistance of faecal Escherichia coli in poultry, poultry farmers and poultry slaughterers', Journal of Antimicrobial Chemotherapy. doi: 10.1093/jac/47.6.763.

Bumbangi, N. F. et al. (2016) 'Occurrence and factors associated with aflatoxin contamination of raw peanuts from Lusaka district's markets, Zambia', Food Control. Elsevier Ltd, 68, pp. 291-296. doi: 10.1016/j.foodcont.2016.04.004.

Byarugaba, D. K. (2004) 'Antimicrobial resistance in developing countries and responsible risk factors', International Journal of Antimicrobial Agents. doi: 10.1016/j.jiantimicag.2004.02.015.

CDC (2016) Foodborne Germs and IIInesses / Food Safety / CDC, CDC.

Centers for Disease Control and Prevention (2018) Antibiotic / Antimicrobial Resistance (AR / AMR), CDC. Chishimba, K. et al. (2016) 'Detection of Extended-Spectrum Beta-Lactamase-Producing Escherichia coli in Market-Ready Chickens in Zambia', International Journal of Microbiology. doi: 10.1155/2016/5275724. 
Chiyangi, H. et al. (2017) 'Identification and antimicrobial resistance patterns of bacterial enteropathogens from children aged 0-59 months at the University Teaching Hospital, Lusaka, Zambia: A prospective cross sectional study', BMC Infectious Diseases. doi: 10.1186/s12879-017-2232-0.

Clarke, K. R. et al. (2012) 'Outbreak of multi-drug resistant salmonella Typhi, lusaka, zambia 2011-2012', American Journal of Tropical Medicine and Hygiene. Conference: 61st Annual Meeting of the American Society of Tropical Medicine and Hygiene, ASTMH.

Cosby, D. E. et al. (2015) 'Salmonella and antimicrobial resistance in broilers: A review', Journal of Applied Poultry Research. doi: 10.3382/japr/pfv038.

Diarrassouba, F. et al. (2007) 'Antibiotic Resistance and Virulence Genes in Commensal Escherichia coli and Salmonella Isolates from Commercial Broiler Chicken Farms', Journal of Food Protection. doi: 10.4315/0362-028X-70.6.1316.

Girlich, D. et al. (2007) 'Extended-spectrum $\beta$-lactamase CTX-M-1 in Escherichia coli isolates from healthy poultry in France', Applied and Environmental Microbiology. doi: 10.1128/AEM.02491-06.

Gordon, M. A. (2008) 'Salmonella infections in immunocompromised adults', Journal of Infection. doi: 10.1016/j.jinf.2008.03.012.

Guetiya Wadoum, R. E. et al. (2016) 'Abusive use of antibiotics in poultry farming in Cameroon and the public health implications', British Poultry Science. doi: 10.1080/00071668.2016.1180668.

Van Immerseel, F. et al. (2004) 'Intermittent long-term shedding and induction of carrier birds after infection of chickens early posthatch with a low or high dose of Salmonella enteritidis', Poultry Science. doi: 10.1093/ps/83.11.1911.

Johnson, J. M., Rajic, A. and McMullen, L. M. (2005) 'Antimicrobial resistance of selected Salmonella isolates from food animals and food in Alberta', Canadian Veterinary Journal.

Kalonda, A. et al. (2015) 'Characterization of Antimicrobial Resistance in Salmonella enterica Serovars Typhi and Paratyphi B in Zambia', Jour of Med Sc \& Tech J Med. Sci. Tech.

Kirby-bauer, T. (1961) 'KIRBY-BAUER TEST FOR ANTIBIOTIC SUSCEPTIBILITY'.

Koluman, A. and Dikici, A. (2013) 'Antimicrobial resistance of emerging foodborne pathogens: Status quo and global trends', Critical Reviews in Microbiology. doi: 10.3109/1040841X.2012.691458.

Lowe, J. (1982) 'Mechanisms of Antibiotic Resistance', Annual Reports in Medicinal Chemistry. doi: $10.1016 /$ S0065-7743(08)60495-9.

Mainda, G. et al. (2015) 'Prevalence and patterns of antimicrobial resistance among Escherichia coli isolated from Zambian dairy cattle across different production systems', Scientific Reports. doi: 
Mainda, G. (2016) Molecular epidemiology of antimicrobial resistance (amr) and shiga toxin producing e coli (stec) in dairy herds of central zambia, PQDT - UK \& Ireland.

Manyi-Loh, C. et al. (2018) 'Antibiotic use in agriculture and its consequential resistance in environmental sources: Potential public health implications', Molecules. doi: 10.3390/molecules23040795.

Mpundu, P. et al. (2019) 'Evaluation of bacterial contamination in dressed chickens in lusaka abattoirs', Frontiers in Public Health. doi: 10.3389/fpubh.2019.00019.

Mshana, S. E., Matee, M. and Rweyemamu, M. (2013) 'Antimicrobial resistance in human and animal pathogens in Zambia, Democratic Republic of Congo, Mozambique and Tanzania: An urgent need of a sustainable surveillance system', Annals of Clinical Microbiology and Antimicrobials. doi: 10.1186/14760711-12-28.

Musaba, E. C. and Mseteka, M. (2014) 'Cost efficiency of small-scale commercial broiler production in Zambia: A stochastic cost frontier approach', Developing Country Studies.

Ngoma, M. et al. (1993) 'Antibiotic resistance of Escherichia coli and Salmonella from apparently healthy slaughtered cattle and pigs, and diseased animals in Zambia', Japanese Journal of Veterinary Research.

Nolan, L. K. et al. (2017) 'Colibacillosis', in Diseases of Poultry: Thirteenth Edition. doi: 10.1002/9781119421481.ch18.

Oie (2007) 'Oie List of Antimicrobials of Veterinary Importance', World Organization for Animal Health. Ramachandran, D., Bhanumathi, R. and Singh, D. V (2017) 'Multiplex PCR for detection of antibiotic resistance genes and the SXT element: application in the characterization of Vibrio cholerae', (2007), pp. 346-351. doi: 10.1099/jmm.0.46655-0.

Replaces, M. et al. (2018) CLSI M100-ED28: 2018 Performance Standards for Antimicrobial Susceptibility Testing , 28th Edition.

van Schaik, W. (2015) 'The human gut resistome', Philosophical Transactions of the Royal Society B: Biological Sciences. doi: 10.1098/rstb.2014.0087.

Talebiyan, R. et al. (2014) 'Multiple antimicrobial resistance of escherichia coli isolated from chickens in Iran', Veterinary Medicine International. doi: 10.1155/2014/491418.

Thapar, N. and Sanderson, I. R. (2004) 'Diarrhoea in children: An interface between developing and developed countries', Lancet. doi: 10.1016/S0140-6736(04)15599-2.

U.S. Food and Drug Administration (FDA) (2001) 'Microbiological Methods \& Bacteriological Analytical Manual (BAM)', U.S. Department of Health and Human Services. 
Vindigni, S. M. et al. (2007) 'Prevalence of foodborne microorganisms in retail foods in Thailand', Foodborne Pathogens and Disease. doi: 10.1089/fpd.2006.0077.

Voidarou, C. et al. (2011) 'Microbial challenges of poultry meat production', Anaerobe. doi: 10.1016/j.anaerobe.2011.05.018.

Weisburg, W. G. et al. (1991) '16S ribosomal DNA amplification for phylogenetic study', Journal of Bacteriology. doi: 10.1128/jb.173.2.697-703.1991.

WHO (2017) WHO updates Essential Medicines List with new advice on use of antibiotics, and adds medicines for hepatitis C, HIV, tuberculosis and cancer., World Health Organization.

WHO Global Report (2014) 'Antimicrobial resistance'.

World Health Organization (WHO) (2015) 'Fact Sheets on Food safety', Who. doi: https://www.who.int/news-room/fact-sheets/detail/food-safety.

$\mathrm{Xu}$, J. et al. (2020) 'Antibiotic use in chicken farms in northwestern China', Antimicrobial Resistance and Infection Control. doi: 10.1186/s13756-019-0672-6.

Yassin, A. K. et al. (2017) 'Antimicrobial resistance in clinical Escherichia coli isolates from poultry and livestock, China', PLoS ONE. doi: 10.1371/journal.pone.0185326.

\section{Supplementary Files}

This is a list of supplementary files associated with this preprint. Click to download.

- ManuscriptSupplementaryMaterial14072020.docx 